\title{
Spatial Variability of Heavy Metals in the Soils of Ahwaz Using Geostatistical Methods
}

\author{
Abbas Hani, Narges Sinaei, and Ali Gholami
}

\begin{abstract}
Heavy metals pollution and their toxic levels in soils is one of the major problems associated with the environment. Like other large cities, Ahwaz, in Southwest of Iran, is exposed to all kinds of environmental pollutions which pose serious problems for human health. A total of 50 soil samples were taken randomly from the surface soils in Ahwaz and the elements of cadmium and lead were measured. Geostatistic and non geostatistic methods were used to determine the spatial distribution. The probability maps were produced using Geographic Information System methods. On the other hand, the Radial Basis Functions is the best interpolation method for $\mathrm{Cd}$ and $\mathrm{Pb}$ with absoluteerrorof 0.209 . About 90percentof study area had more cadmium pollution than standard levels while $\mathrm{Pb}$ contamination in about 33 percent of the study area is more than standard levels.
\end{abstract}

Index Terms-Ahwaz, environmental pollution, geostatistics, heavy metals.

\section{INTRODUCTION}

Soil can naturally have high concentration of heavy metals due to the weathering of parent material. Industrialization and urbanization have transferred heavy metals into the environment. They are produced from a variety of natural and anthropogenic sources, such as atmospheric deposition, geologic weathering, agricultural activities, and residential and industrial products [1]. Studies of urban soils heavy metals contaminations carried out on a number of cities, have found elevated levels of heavy metals from anthropogenic sources [2]-[4]. Physical and chemical properties of urban soils are affected by anthropogenic activities such as smelting, motor vehicles, domestic activities and waste disposal.

Spatial distribution and source identification of heavy metals in soils are essential for identification of the hot-spot areas of pollution and to assess the potential sources of pollutants. Heavy metal pollution in soils is commonly estimated by interpolating concentrations of heavy metals sampled at point locations so that each heavy metal is represented in a separate map [5]. The methods of geostatistics use the stochastic theory of spatial correlation for both interpolation and apportioning uncertainty [6].

Geostatistics provides an advanced methodology that facilitates quantification of the spatial features of soil parameters and enables spatial interpolation [7]. In particular,

Manuscript received September 9, 2013; revised November 10, 2013 This work was supported by Islamic Azad University, Science and Research Branch Laboratories

Abbas Hani is with the Department of Soil Science, Saveh Branch, Islamic Azad University, Saveh, Iran (email: abbas_hani@iau-saveh.ac.ir).

Narges Sinaei and Ali Gholami are with Department of Soil Science, Khozestan Science and Researh Branch, Islamic Azad University, Khozestan, Iran (email: Sinaei_n@yahoo.com, ali.gholami54@gmail.com). geostatistics has been popularly applied in investigating and mapping soil pollution by heavy metals in recent years [8], [9]. Geostatistics uses the understanding of statistical variation as an important source of information for improving the estimation of an attribute at unsampled locations, given a limited set of measurements. The geostatistical methods consider the spatio-temporal variation of soil properties as a random process depending on both the time and space. In fact, these methods provide a set of statistical tools for incorporating spatial coordinates of observations in data processing [6]. The tools are useful for the study of spatial uncertainty and hazard assessment. Geostatistical analysis considers the concentration of a potentially hazardous element in an affected medium as a regionalized variable in space and attempts to compute and model the variogram, as well as to predict the concentration in non-sampled areas using kriging and statistical analysis of errors [10]. Some studies have attempted to apply both multivariate analyses and Geographical Information System (GIS) techniques in soils of big cities [11]. Geostatistical analysis, such as ordinary kriging, disjunctive kriging and indicator kriging have been widely used to study environmental pollution of soils [12], [13]. One of the most widely used nonparametric geostatistical methods is Indicator kriging (IK) which assumes no precondition on distributions of variables and uses a binary indicator transformation of data to make the predictor less sensitive to outliers [14].

No detailed studies have been undertaken to determinate the heavy metal levels in Ahwaz, southwestern Iran. Thus, The objectives of the this study were to determine: 1) the concentrations of $\mathrm{Pb}, \mathrm{Cd}, \mathrm{Mn}$, and $\mathrm{Fe}$ in top soils of Ahwaz, 2) heavy metals distribution through geostatistical analysis to identify their spatial patterns in the region and mapping of the environmental quality and risk assessment, and 3) natural or anthropic sources of individual metals in the soils using geostatistical and multivariate statistical analyses.

\section{MATERIAL AND METHOD}

\section{A. Study Area and Sampling}

Ahwaz is located in the southwest of Iran $\left(35^{\circ} 33^{\prime} 39^{\prime \prime}\right.$ $35^{\circ} 24^{\prime} 15^{\prime \prime} \mathrm{N}, 51^{\circ} 35^{\prime} 29^{\prime \prime} \sim 51^{\circ} 25^{\prime} 03$ "E) with an area of $200 \mathrm{~km}^{2}$ (Fig. 1). It has approximately 1133000 inhabitants and has a long industrial history, mainly steel and oil industries. Climate of the area is dry with an annual average temperature of $23{ }^{\circ} \mathrm{C}$ and an average annual rainfall of 590 $\mathrm{mm}$. There are about 60 metal smelting, power plants, petroleum processing and chemicals industries from which heavy metals are emitted into the environment. These have been identified as a possible point of elemental pollution, hence elevated levels of heavy metals pollution $(\mathrm{Pb}, \mathrm{Cd}, \mathrm{Mn}$, and $\mathrm{Fe}$ ). 


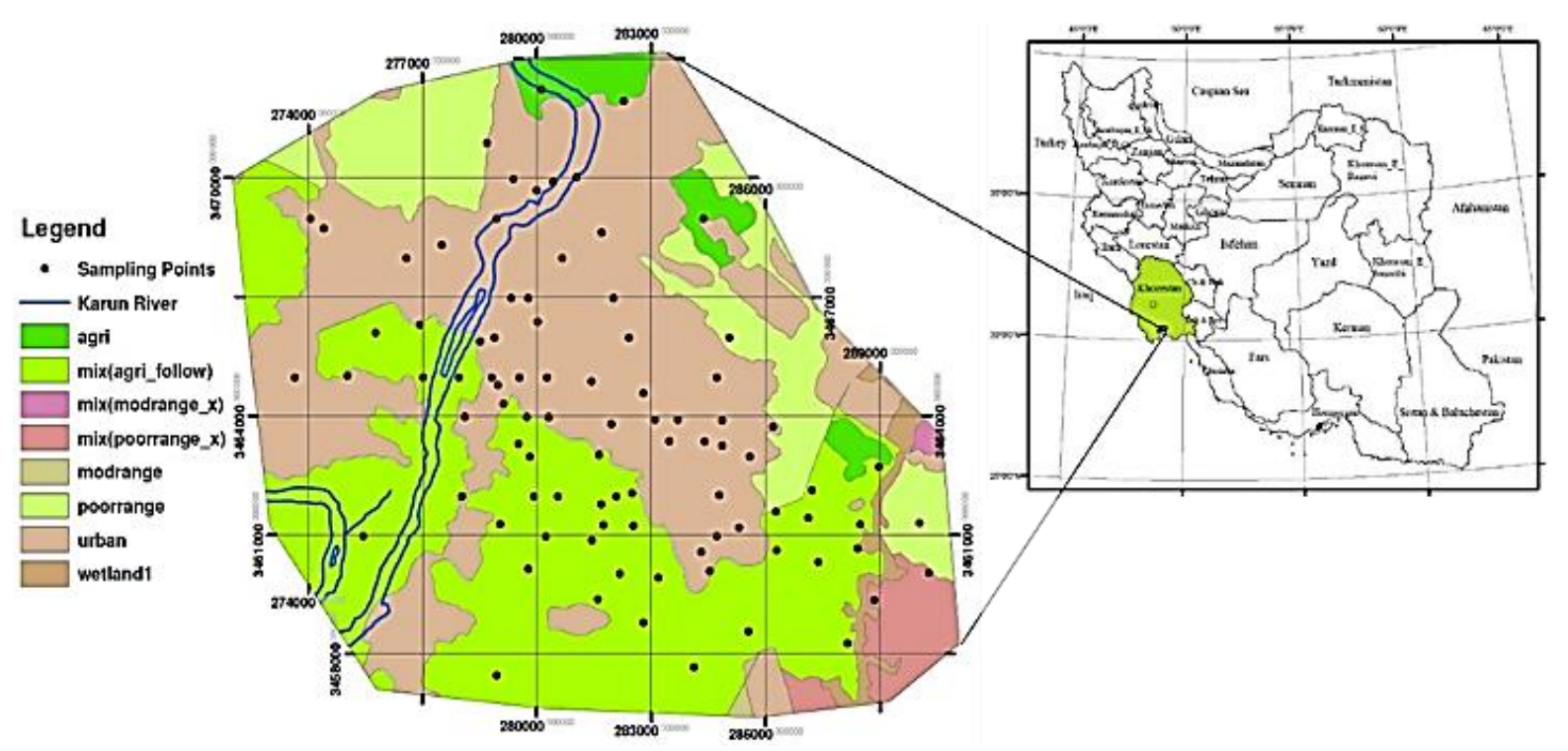

Fig. 1. Land use (sampling point) and satellite maps of Ahwaz.

\section{B. Sampling and Chemical Analysis}

In July 2011, a total of 90 surface soil samples $(0-25 \mathrm{~cm}$ in depth) were taken from soils based on a land use map at 1:100,000 scale (Fig. 1). Sampling sites were selected randomly and soil samples were taken at a depth of $0-15 \mathrm{~cm}$ and air-dried. Samples came from urban or rural areas of different land use. Positions of sampling sites were recorded by the aid of a Global Positioning System (GPS) receiver. Approximately $1 \mathrm{~kg}$ of each sample was stored in polyethylene packages and transported to the laboratory. The soil samples were air - dried for several days at room temperature $\left(20-22{ }^{\circ} \mathrm{C}\right)$ and then ground and sieved to a size of $2 \mathrm{~mm}$ for analysis of their properties. The samples were digested with $\mathrm{HNO} 3-\mathrm{H} 2 \mathrm{O} 2-\mathrm{HCl}$ according to US EPA method 3050B [15]. Total contents of heavy metals were analyzed by inductively coupled plasma mass spectrometry (ICPMS) for $\mathrm{Cu}$ and $\mathrm{Cd}$, by absorption fluorescence spectrometry (AFS). The heavy metal concentrations of $\mathrm{Pb}$, $\mathrm{Mn}$, and $\mathrm{Fe}$ were determined using inductively coupled plasma atomic emission spectroscopy (ICP-ES; 138 Ultrace; Jobin Yvon) and those of $\mathrm{Cd}$ with a graphite furnace atomic absorption spectrometer.

\section{Geostatistics}

Geostatistics uses the variogram technique to measure the spatial variability of the recognized variables and provides the input parameters for the spatial interpolation of kriging [5]. Kriging has been widely used as an important interpolation method at different scales, especially in studies on soil pollution [3]. The semivariance $\gamma(h)$, is calculate as (1):

$$
\gamma(h)=\frac{1}{2 n(h)} \sum_{i=1}^{n(h)}\left[z\left(x_{i}\right)-z\left(x_{i}\right)-z\left(x_{i+h}\right)\right]^{2}
$$

where $h$ is the step width, $n(h)$ the number of sample pairs at each step width $h, z\left(x_{i}\right)$ the realization of the random function at location $i$, and $z\left(x_{i+h}\right)$ the realization of the random function at location $(i+h)$ [5]. The experimental variogram measures the average degree of dissimilarity between unsampled values and nearby data values and can thus depict autocorrelation at various distances. The variogram model was chosen from a set of mathematical functions that describe spatial relationships and usually fitted by weighted lost squares, and range, nugget and sill are then used in the kriging procedure. In this study, to make distribution maps, several spatial interpolation techniques were evaluated for the best results including kriging, global/local polynomial interpolation (G/LPI), inverse distance weighting (IDW) and radial basis functions (RBF). The predicted values by indicator kriging show the probability that variables do not exceed beyond the defined threshold. In Indicator kriging, soil variable is coded as indicator values 1 and 0 at a threshold value [6]. The spatial variable $Z\left(u_{\alpha}\right)$ at a given location $\left(u_{\alpha}\right)$ with a threshold $\operatorname{value}\left(z_{r}\right)$, is transformed into an indicator variable with a binary distribution is calculate as (2):

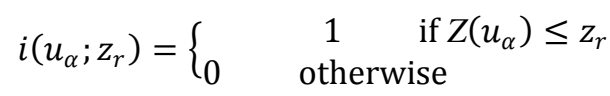

In our study, threshold values were equal to the maximum allowable concentrations of heavy metals in soils and they were chosen according to the evaluation of the degree simulation quality and the model-experiment comparison of different model approaches, cross-validation indicators and additional model parameters can be used. For comparing these models, we used cross validation by the statistical parameters Root Mean Squared Error (RMSE) Mean Bias Error (MBE) and Mean Absolute Error (MAE) as shown in (3), (4) and (5):

$$
\begin{aligned}
M B E & =\frac{1}{n} \sum_{i=1}^{n}\left[z\left(x_{i}\right)-Z \times\left(x_{i}\right)\right]^{2} \\
M A E & =\frac{1}{n} \sum_{i=1}^{n}\left|z\left(x_{i}\right)-Z \times\left(x_{i}\right)\right| \\
R M S E & =\sqrt{\frac{1}{n} \sum_{i=1}^{n}\left[z\left(x_{i}\right)-Z \times\left(x_{i}\right)\right]^{2}}
\end{aligned}
$$

where $z\left(x_{i}\right)$ is actual soil variable, $Z \times\left(x_{i}\right)$ its estimate and $\mathrm{n}$ is soil variable data [16]. MBE is used for determining the degree of bias in the estimates, often referred to as the bias, but it should be used cautiously as an indicator of accuracy because negative and positive estimates counteract each other, and the resultant MBE tends to be lower than the actual 
error.

\section{Transformation and Statistical Analysis}

Logarithmic transformations were applied to normalize too highly skewed and outlier data sets because they can impair the variogram structure and the kriging results; however, normality may be strictly required in multivariate statistics and linear geostatistics [7]. Pearson correlation coefficients were applied to examine the relationships between soil heavy metals. Also, principal components analysis (PCA) was employed for identification of heavy metal sources. PCA converts the variables under investigation into factors, or principal components, and correlation matrix was used to identify the relationship between variables. Correlation among the original variables minimizes the elements dividing them into fewer groups. The application of varimax rotation of standardized component loadings enabled us to obtain a clear system as a result of the maximization of component loadings variance [17].

Descriptive statistical parameters of the data were performed using the SPSS 15.0 for Windows. Geostatistical analysis, semivariogram model fitting, and spatial distribution using ordinary kriging were performed with GIS software ArcGIS V.9.2 (ESRI Co, Redlands, USA).

\section{RESUlT AND DisCUSSION}

Table I gives the basic descriptive statistics for data sets for heavy metals. It is shown that the skewness and kurtosis values for $\mathrm{Cd}$ and $\mathrm{Cr}$ were low, whereas these parameters in $\mathrm{Pb}, \mathrm{Mn}$ and $\mathrm{Fe}$ were high and not normally distributed. Because of statistics and geostatistics analyses, the data is required to follow a normal distribution. The significance levels of the Kolmogorov-Smirnov normality test for the raw data and the logarithmically transformed significance are shown in Table I. The coefficients of variation of $\mathrm{Pb}, \mathrm{Cd}$ and Fe were $65.03 \%, 70.32 \%$ and $82.73 \%$, respectively which had greater variation among the soil heavy metals. Average values of the soil as reference values were used to evaluate pollution due to human influence [18]. Compared with the average values of the crust $\mathrm{Pb}$ and $\mathrm{Cd}$ had enriched values in Ahwaz soils. Based on the Netherlands Department of Soil Protection, the guide values for $\mathrm{Pb}$ and $\mathrm{Cd}$, were $85 \mathrm{mg} \mathrm{kg}-1$, $0.8 \mathrm{mg} \mathrm{kg}-1$, respectively. The average value for soil $\mathrm{Pb}$ in Ahwaz soils was 72.95, which just fell on these scopes. It was displayed that concentrations in 21 samples exceeded the guide value for $\mathrm{Pb}$.

TABLE I: SOME STATISTICAL PARAMETERS FOR SOIL HEAVy METALS

\begin{tabular}{ccccc}
\hline Statistical parameter & $\mathrm{Pb}$ & $\mathrm{Mn}$ & $\mathrm{Fe}$ & $\mathrm{Cd}$ \\
\hline Mean & 72.95 & 286.66 & 22701.73 & 3.36 \\
Median & 57.40 & 253.30 & 18921.00 & 3.00 \\
SD & 47.45 & 151.09 & 18713.03 & 2.37 \\
Maximum & 246.60 & 976.50 & 108771.00 & 9.60 \\
Minimum & 0.60 & 126.20 & 1675.20 & 0.10 \\
Skewness & 1.96 & 3.13 & 3.16 & 0.83 \\
Kurtosis & 4.14 & 11.12 & 10.79 & 0.16 \\
C.V. (\%) & 65.03 & 52.67 & 82.73 & 70.32 \\
Standard value & 85 & - & - & 0.80 \\
K-S p & 0.000 & 0.000 & 0.00 & 0.161 \\
Log K-S p & 0.192 & 0.117 & 0.065 & - \\
\hline
\end{tabular}

$\overline{{ }^{a} \text { [17] SD: standard deviation, K-S test: Kolmogorov-Smirnov test. }}$
The results showed that $\mathrm{Cd}, \mathrm{Cr}$, and $\mathrm{Ni}$ had passed the Kolmogoro-Smirnov normality test $(K-S p<0.05)$, but $\mathrm{Pb}$ had not passed. Since further geostatistic analysis needs data to follow a normal distribution, data transformation was carried out prior to the next analysis. The lowest CV\% that we found for $\mathrm{Cr}, \mathrm{Cd}$ and $\mathrm{Ni}$ exhibited weak variation, and their content was almost constant in the study location, suggesting that their presence is probably due to lithogenic process. Additionally, $\mathrm{Cr}, \mathrm{Cd}$, and $\mathrm{Ni}$ levels were likely controlled by the same parent material. The $\mathrm{Pb}$ measurement values were transformed log normally due to the highly skewness and $\mathrm{Cd}, \mathrm{Cr}$, and $\mathrm{Ni}$ followed normal distribution. However, some urban soils studies [19] showed higher $\mathrm{Cd}$ concentration.

According to the results of PCA, the original variables could be reduced to three factors (F1, F2 and F3), which accounted for $58.023 \%$ of the total variances (Table II). The factors obtained were rotated using a varimax-normalized algorithm that enables easier interpretation of the loadings of the principal components. Based on the PC loadings, the first group (F1) included $\mathrm{Pb}$ which had anthropogenic sources, the second group (F2) included $\mathrm{Cd}$ with natural process and finally, Fe and Mn had intermediate sources (pedogenic and anthropogenic).

TABLE II: TOTAL VARIANCE EXPLAINED AND COMPONENT MATRIXES (THREE PRINCIPAL COMPONENTS SELECTED) FOR HEAVy METAL CONTENTS

\begin{tabular}{cccc}
\hline \multicolumn{3}{c}{ Initial Eigenvalues } & Component \\
$\begin{array}{c}\text { Cumulative } \\
(\%)\end{array}$ & $\begin{array}{c}\% \\
\text { of Variance }\end{array}$ & Total & \\
\hline \multirow{2}{*}{22.815} & 22.815 & 1.369 & 1 \\
40.692 & 17.877 & 1.073 & 2 \\
58.023 & 17.331 & 1.040 & 3 \\
73.558 & 15.535 & 0.932 & 4 \\
88.321 & 14.763 & 0.886 & 5 \\
100.000 & 11.679 & 0.701 & 6
\end{tabular}

\begin{tabular}{|c|c|c|c|c|c|}
\hline \multicolumn{3}{|c|}{$\begin{array}{c}\text { Extraction Sums of Squared } \\
\text { Loadings }\end{array}$} & \multicolumn{3}{|c|}{$\begin{array}{c}\text { Rotation Sums of Squared } \\
\text { Loadings }\end{array}$} \\
\hline Total & $\begin{array}{c}\% \\
\text { of } \\
\text { Variance } \\
\end{array}$ & $\begin{array}{c}\text { Cumulative } \\
(\%)\end{array}$ & Total & $\begin{array}{c}\% \\
\text { of } \\
\text { Variance }\end{array}$ & $\begin{array}{c}\text { Cumulative } \\
(\%)\end{array}$ \\
\hline 1.369 & 22.815 & 22.815 & 1.303 & 21.718 & 21.718 \\
\hline 1.073 & 17.877 & 40.692 & 1.105 & 18.410 & 40.127 \\
\hline 1.040 & 17.331 & 58.023 & 1.074 & 17.896 & 58.023 \\
\hline
\end{tabular}

\section{A. Geostatistical Analysis}

The semivariogram experiment depicts the variance of the sample values at various separation distances. The ratio of nugget to sill (nugget/sill) can be used to express the extent of spatial autocorrelations of environmental factors. If the ratio is low $(<25 \%)$, the variable has strong spatial autocorrelations at a regional scale, between $25 \%$ and $75 \%$, the variable has moderate spatial dependence. A high ratio of the nugget effect $(>75 \%)$ indicates spatial heterogeneity and shows only weak spatial dependence (Table III).

The results showed that $\mathrm{Cd}$ was fitted with Exponential 
mode. A Spherical model was found to be Fe and finally Mn and $\mathrm{Pb}$ were fitted with Gaussian and linear models, respectively. The fitted model provides information about the spatial structure as well as the input parameters for kriging interpolation [19]. The range for all elements except Mn was around less than $1 \mathrm{~km}$. So, there was no high spatial correlation of the elements over the complete region. The ratio of nugget to sill for $\mathrm{Pb}$ was more than 0.75 , showing weak spatial dependence. The ratios for $\mathrm{Cd}, \mathrm{Mn}$ and $\mathrm{Fe}$ were between 0.25 and 0.75 , showing moderate spatial dependence which indicates that extrinsic factors (such as industrial pollution) may have affected their spatial correlations. The distribution maps of heavy metals including $\mathrm{Pb}, \mathrm{Cd}, \mathrm{Mn}$ and Fe concentrations are illustrated in Fig. 2. These maps show the spatial variation of heavy metal concentrations generated from their semivariograms.

\begin{tabular}{|c|c|c|c|c|c|}
\hline $\begin{array}{l}\text { Heavy } \\
\text { metals }\end{array}$ & $\begin{array}{l}\text { Best fitted } \\
\text { model }\end{array}$ & $\begin{array}{c}\text { Nugge } \\
\mathrm{t} \\
\left(\mathrm{C}_{0}\right)\end{array}$ & $\begin{array}{c}\text { Sill } \\
\left(\mathrm{C}_{0}+\mathrm{C}\right)\end{array}$ & $\begin{array}{c}\left(\mathrm{C}_{0}\right) / \\
\left(\mathrm{C}_{0}+\mathrm{C}\right)\end{array}$ & $\mathrm{R}^{2}$ \\
\hline $\mathrm{Pb}$ & Linear & 16.27 & 21.41 & 0.76 & 0.58 \\
\hline $\mathrm{Cd}$ & Spherical & 0.328 & 0.845 & 0.39 & 0.65 \\
\hline $\mathrm{Cr}$ & $\begin{array}{l}\text { Exponenti } \\
\text { al }\end{array}$ & 122.99 & 683.28 & 0.18 & 0.86 \\
\hline $\mathrm{Mn}$ & Gaussian & 8.56 & 23.78 & 0.36 & 0.87 \\
\hline $\mathrm{Fe}$ & $\begin{array}{c}\text { Exponenti } \\
\text { al }\end{array}$ & 63.21 & 150.50 & 0.42 & 0.74 \\
\hline $\mathrm{Ni}$ & Spherical & 2.56 & 3.16 & 0.81 & 0.56 \\
\hline
\end{tabular}
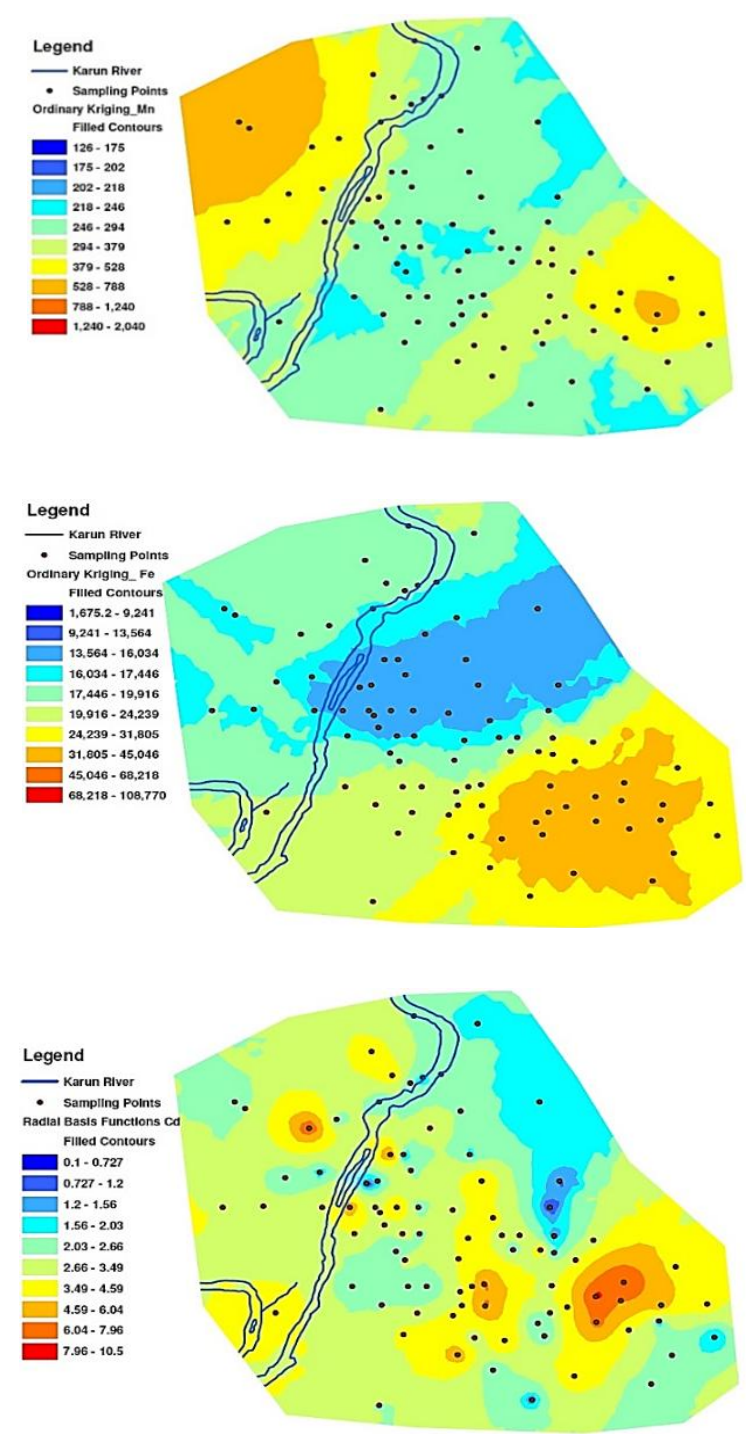

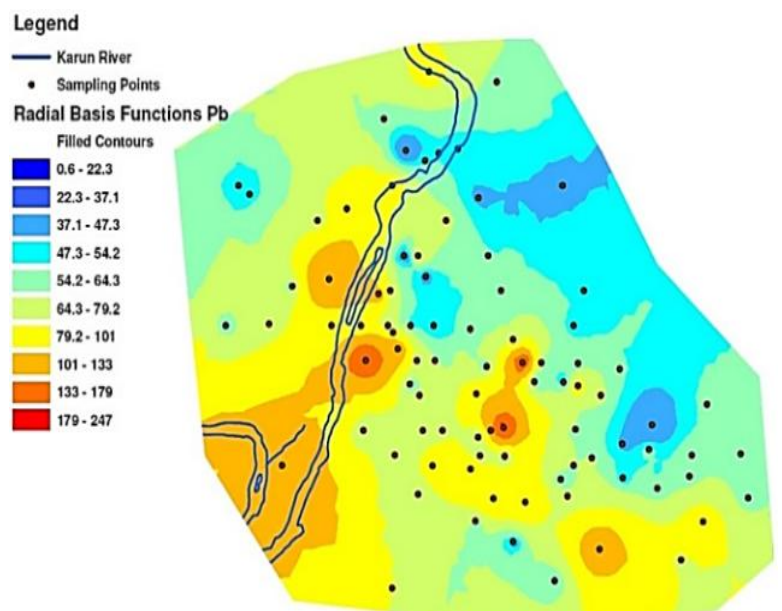

Fig. 2. The estimated probability maps of $\mathrm{Pb}, \mathrm{Mn}, \mathrm{Fe}$ and $\mathrm{Cd}$.

Predictive performances of the fitted models were checked on the basis of cross validation. Table III shows the estimated MAE, MBE and RMSE values by IDW, LPI, RBF and OK method interpolations. RBF was selected as interpolation method for $\mathrm{Pb}, \mathrm{Cd}, \mathrm{Cr}, \mathrm{Mn}$ and $\mathrm{Fe}$ with the lowest errors while the estimated probability maps of $\mathrm{Ni}$ was produced by OK (Table IV).

\begin{tabular}{|c|c|c|c|c|}
\hline \multirow{2}{*}{$\begin{array}{l}\text { Heavy } \\
\text { metals }\end{array}$} & \multirow{2}{*}{$\begin{array}{c}\text { Method } \\
\text { interpolation }\end{array}$} & \multicolumn{3}{|c|}{ Errors } \\
\hline & & MAE & MBE & RMSE \\
\hline $\mathrm{Pb}$ & OK & 0.209 & 0.006 & 0.313 \\
\hline $\mathrm{Cd}$ & OK & 1.283 & 0.029 & 1.535 \\
\hline $\mathrm{Mn}$ & OK & 2.13 & 0.003 & 0.281 \\
\hline $\mathrm{Fe}$ & $\mathrm{OK}$ & 2.052 & 1.248 & 2.630 \\
\hline
\end{tabular}

Fig. 2 presents the spatial patterns of six heavy metals in soils of Ahwaz. The spatial distribution maps for $\mathrm{Ni}$ and $\mathrm{Pb}$ showed similar spatial trends with low concentrations in north area and high concentrations in south area. Moreover, it was found that the highest distribution of Fe had one part with a clear boundary almost along the northwest area and the lowest clear boundary in southeast area. The highest concentration of $\mathrm{Mn}$ was located in the northwest part of Ahwaz, while, $\mathrm{Cr}$ and $\mathrm{Cd}$ had highest concentration in north part of the city.

\section{CONCLUSIONS}

The assessment of pollution in Ahwaz has revealed some critical environmental situations with increased heavy metal concentrations. Among the four metals, $\mathrm{Cd}$ and $\mathrm{Pb}$ had high risk for environment pollution and human health. The sources of different heavy metals in urban topsoils are related to traffic, industry and natural substances. Based on the heavy metals concentrations and geostatistics, $\mathrm{Pb}$ is controlled by anthropogenic activity connected with traffic and industries. While $\mathrm{Cd}$ is controlled by anthropogenic and pedogenic sources. In addition, the average concentrations of the study area heavy metals, with the exception of $\mathrm{Cd}$, were lower than the standard value concentrations. The probability map produced based on kriging interpolation gives a spatial structure analysis and a view of soil heavy metals changes by contour maps. 


\section{REFERENCES}

[1] A. Demirak, F. Yilmaz, and A. L.Tuna, "Heavy metals in water, sediment and tissues of leuciscus cephalus from a stream in southwestern Turkey," Chemosphere, vol. 63, pp. 1451-1458, 2006.

[2] H. Taghipour, M. Mosaferi, F. Armanfar, and S. J. Gaemmagami, "Heavy metals pollution in the soils of suburban areas in big cities: a case study," Int. J. Environ. Sci. Technol., vol. 10, pp. 243-250, 2013.

[3] T. Chen, X. M. Liu, M. Z. Zhu et al., "Identification of trace element sources and associated risk assessment in vegetable soils of the urban-rural transitional area of Hangzhou, China," Environ. Pollut, vol. 151, pp. 67-78, 2008.

[4] A. K. Krishna and P. K. Govil, "Assessment of heavy metal contamination in soils around Manali industrial area, Chennai, Southern India,” Environ. Geol, vol. 54, pp. 1465-1472, 2008.

[5] R. Webster and M. Oliver, Geostatistics for Environmental Scientists, New York: John Wiley and Sons, 2001, pp. 271.

[6] P. Goovaerts, Geostatistics for Natural Resource Evaluation, New York: Oxford University, 1997.

[7] USEPA, SW-846 Reference Methodology: Method 3050b. Standard Operating Procedure for the Digestion of Soil/Sediment Samples Using a Hotplate/Beaker Digestion Technique, Chicago, Illinois, 1999.

[8] D. McGrath, C. S. Zhang, and O. Carton, "Geostatistical analyses and hazard assessment on soil lead in Silvermines, area Ireland," Environ. Pollut, vol. 127, pp. 239-248, 2004.

[9] Y. P. Lin, T. K. Chang, C. W. Shih, and C. H. Tseng, "Factorial and indicator kriging methods using a geographic information system to delineate spatial variation and pollution sources of soil heavy metals," Environ. Geol, vol. 42, pp. 900-909, 2002.

[10] C. W. Liu, C. S. Jang, and C. M. Liao, "Evaluation of arsenic contamination potential using indicator kriging in the Yun-Lin aquifer (Taiwan)," Sci. Total Environ., vol. 321, pp. 173-88, 2004.

[11] A. Papoulis and S. U. Pillai, Probability, Random Variables and Stochastic Processes, 4th ed. New York: McGraw-Hill, 2002.

[12] C. S. Zhang, "Using multivariate analyses and GIS to identify pollutants and their spatial patterns in urban soils in Galway, Ireland," Environ. Pollut, vol. 142, pp. 501-511, 2006.

[13] B. Y. Cheng, W. T. Fang, G. S. Shyu, and T. K. Chang, "Distribution of heavy metals in the sediments of agricultural fields adjacent to urban areas in Central Taiwan," Paddy Water Environ., vol. 11, pp. 343-351, 2013.

[14] S. J. Cheng, "Use of multivariate indicator kriging methods for assessing groundwater contamination extents for irrigation," Environ. Monit Assess., vol. 185, no. 5, 4049-4061, 2013.

[15] K. W. Juang and D. Y. Lee, "Simple indicator kriging for estimating the probability of incorrectly delineating hazardous areas in a contaminated site," Environ. Sci. Technol., vol. 32, pp. 2487-2493, 1998.

[16] F. L'opez-Granados, M. Jurado-Exp'osito, S. Atenciano, A. Garc' 1a-Ferrer, De. La. S'anchez, M. Orden, and L. Garc'1a-Torres, "Spatial variability of agricultural soil parameters in southern Spain," Plant Soil, vol. 246, pp. 97-105, 2002.
[17] Department of Soil Protection, "The Netherlands Soil Contamination Guidelines, Netherlands Intervention Values for Soil Remediation,' Reference no. DBO/07494013, Amsterdam, the Netherlands, 1994.

[18] Y. M. Zheng, T. B. Chen, and J. Z. He, "Multivariate geostatistical analysis of heavy metal in top soils from Beijing, China," J. Soil Sediment, vol. 8, no. 1, pp. 51-58, 2008.

[19] P. Burgos, E. Madejón, A. Pérez-de-Mora, and F. Cabrera, "Spatial variability of the chemical characteristics of a trace elementcontaminated soil before and after remediation," Geoderma, vol. 130, pp. $157-175,2006$.

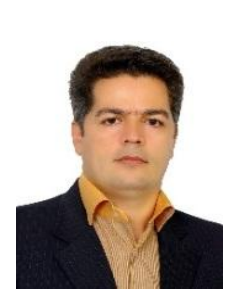

Abbas Hani was born in Saveh city in Iran on March 24, 1976. He was graduated with Bachelor Degree in Agriculture Engineering-Soil Science in 2000 and in Master of Science in Soil Science in 2002 from Ahvaz University. He was graduated as Ph.D. in faculty of Agriculture and Natural Resources, department of Soil Science, Islamic Azad University, Science and Research Branch in Tehran in 2010. He is a faculty member of Islamic Azad university, Saveh Branch in Saveh city of Markazi province) since 2003 and now he is studying his thesis in field of Soil and Environmental Pollution and Assessments.

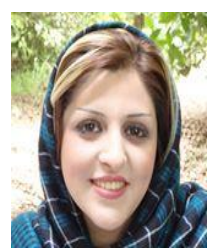

Narges Sinaei graduated in Master of Environmental Science in 2012 from Islamic Azad University, Khuzestan Science and Research Branch.

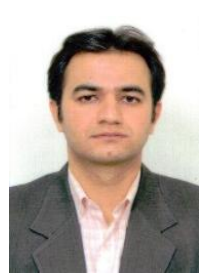

Ali Gholami was born in Tehran city in Iran on February 19, 1976. He was graduated with Bachelor Degree in Agriculture Engineering-Soil Science in 2000 and in Master of Science in Soil Science in 2005 from Islamic Azad University in Iran in Isfahan province. He graduated as Ph.D. in faculty of Agriculture and Natural Resources, department of Soil Science, Islamic Azad university, Science and Research Branch in Tehran in 2006 and academic member of Islamic Azad University, Khuzestan Science and Research Branch in Ahwaz city of Khuzestan province in 2007 and now he is studying his thesis in field of land use changes and its influence on soil physical, chemical and mineralogy characteristics. He was selected as the manager of soil science department and research office in Islamic Azad University, Khuzestan Science and Research Branch in 2009 and it now. 